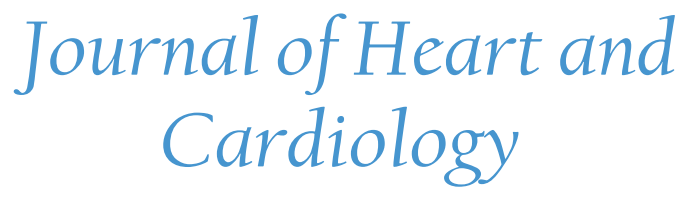

\title{
Long-Term Outcomes after Percutaneous Mitral Valvu- loplasty in Colombia, South America
}

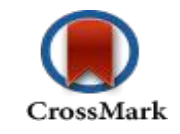

\author{
Carlos Uribe $^{1}$, Wajeeha Saeed ${ }^{2 *}$, Carlos Tenorio ${ }^{1}$, Carlos Eusse Carlos ${ }^{1}$, Carlos Rubio ${ }^{1}$, Julián A Ochoa ${ }^{3}$, \\ Roland Njoh ${ }^{4}$, Muhammad Rizwan Sardar ${ }^{4}$, Bernardo Lombo ${ }^{5}$, John K Forrest ${ }^{5}$
}

${ }^{1}$ Interventional Cardiology Unit, Cardio Vid Clinic, Medellín, Colombia, South America

${ }^{2}$ Department of Medicine, Albert Einstein College of Medicine, Bronx, New York

${ }^{3}$ Interventional Cardiology Unit, Valle de Lilli foundation, Cali, Colombia, South America

${ }^{4}$ Interventional Cardiology, Cooper University Hospital, Camden, New Jersey

${ }^{5}$ Yale School of Medicine, New Haven, Connecticut, USA

"Corresponding Author: Wajeeha Saeed, Department of Medicine, Albert Einstein College of Medicine, 1650 Grand Concourse, Bronx, New York, NY 10457. Tel: +1 347-327-2736; E-mail: wajsaeed@yahoo.com

\begin{abstract}
Objective: To evaluate the long term clinical results of percutaneous mitral balloon valvuloplasty in patients with rheumatic mitral stenosis in Colombia, South America. Background: In 1993, Colombia, South America began a National Mitral Balloon Valvuloplasty Registry. This multicenter database was designed to establish the longterm safety and efficacy of percutaneous mitral valvuloplasty, as well as rate of restenosis. Methods: Between January 1993 and December 2011, 182 patients $>18$ years old were treated for rheumatic mitral stenosis with percutaneous valvuloplasty in two centers in Colombia, South America. Clinical, echocardiographic and hemodynamic data were stored in an electronic database. The Inoue Balloon technique was used in $99 \%$ of patients. The longest follow-up period was 15 years.

Results: 182 patients were included; women (89\%), hypertension (19\%), dyslipidemia $(1.6 \%)$, smoking $(8.8 \%)$, diabetes $(5.5 \%)$ and renal failure $(1 \%)$. Forty-six patients $(25.7 \%)$ were NYHA functional class III-IV. Procedure related mortality was $1.09 \%$ (2 patients). Fourteen patients $(7.69 \%)$ had significant post procedure mitral insufficiency (grades III-IV); 4 patients $(2.19 \%)$ had cardiac tamponade and 6 patients $(3.3 \%)$ had vascular site related complications. The survival rate at 12 months was $96 \%$. At 50 months, $60.7 \%$ of patients were alive and free of mitral surgery and repeated mitral valvuloplasty. The percentage of severe restenosis of mitral valve was $4.8 \%, 19.2 \%, 15.2 \%$ at one, five and 10 years of follow-up.

Conclusions: Percutaneous mitral valvuloplasty using the Inoue balloon technique improves the hemodynamic profile of severe mitral stenosis. Long-term follow-up suggest that it is a safe alternative to mitral valve surgery in well selected patients.
\end{abstract}

Received date: July 07, 2015

Accepted date: Aug 31, 2015

Published date: Sep 10, 2015

Citation: Saeed, W., et al. Long-term Outcomes after Percutaneous Mitral Valvuloplasty in Colombia, South America. (2015) J Heart Cardiol 1(2): 34-38.

Keywords: Adult; Catheterization/ methods; Disease Free-Survival; Hemodynamics; Mitral Valve Stenosis/mortality; Mitral Valve Stenosis/physiopathology; Mitral Valve Stenosis/therapy; Registries; Prospective Studies

Abbreviations: SD: Standard Deviation; NYHA: New York Heart Association; TAVI= Transcatheter Aortic-Valve Implantation; $\mathrm{PMBV}=$ Percutaneous $\mathrm{Mi}$ tral balloon Valvuloplasty; $\mathrm{MS}=$ Mitral Stenosis

\section{Introduction}

Structural heart disease leads to significant morbidity and mortality if left untreated with variable causes depending on age group and geographical location. In the pediatric population, structural heart diseases are due to congenital anomalies. In developing countries, rheumatic carditis is a leading source while in the western countries and elderly, the leading problem is calcium deposition on valves and ischemia induced valvular changes. Treatment approaches include open-heart surgery and percutaneous interventions. With respect to valve stenosis, there have been revolutional changes in catheter techniques such as Transcatheter Aortic-Valve Implantation (TAVI) for patients deemed at high risk for traditional aortic valve replacement and the institution of the Inoue approach 
for mitral stenosis. The treatment of mitral stenosis depends on the postulated cause.

Rheumatic fever is the most prevalent cause of mitral stenosis (MS) ${ }^{[1]}$. Cardiac rheumatic disease is a chronic manifestation of rheumatic carditis, which occurs between 60 and $90 \%$ of cases in rheumatic fever ${ }^{[2-4]}$. Rheumatic mitral valvular disease continues to be an important public health problem, especially because it is a preventable disease; furthermore its incidence continues to grow in many developing third world countries. In Colombia, it is estimated that between 0.1 and $0.2 \%$ of deaths occur as a result of rheumatic disease ${ }^{[5]}$. Delay in the treatment of MS leads to complications like atrial fibrillation and pulmonary hypertension ${ }^{[6-8]}$. In 1984, Inoue et al described the first percutaneous mitral balloon valvuloplasty (PMBV) and since then, the Inoue technique has been shown to produce excellent hemodynamic results in patients with severe rheumatic mitral stenosis $^{[9]}$. Multiple trials have been done comparing PMBV to surgical mitral valvotomy with follow-up ranging from one to seven years ${ }^{[10-21]}$. A recent meta-analysis showed comparable clinical outcomes between the two approaches ${ }^{[22]}$. The external validity of the clinical trials are one of the most important aspect which are often ignored in the current cardiovascular literature and expert guidelines ${ }^{[23,24]}$. The long-term follow-up data in mitral stenosis patients undergoing PMBV is not available for a country like Colombia, which is a third world country ${ }^{[3]}$. To address this, in 1993 the Colombian Mitral Balloon Valvuloplasty registry was created to collect baseline, post-procedural as well as long-term follow-up data of patients undergoing PMBV. We therefore seek to analyze the long-term clinical results of PMBV in patients.

\section{Methods}

Data collection: The data is collected from two largest participating centers of the Colombian Mitral stenosis registry, where an institutional committee has approved the PMBV for Rheumatic mitral stenosis patients. All patients were $\geq 18$ years old, known to have severe rheumatic mitral stenosis according to clinical, echocardiographic ${ }^{[25]}$ and hemodynamic parameters. The registry collected data of all MS patients undergoing PMBV from January 1993 to December 2011. The registry ended after a maximum follow-up of 15 years. We retrospectively reviewed each patient clinical history and follow-up information was collected at the time of discharge, one month, six months, one year and yearly thereafter. A committee reviewed all the medical records of the patients that died for adjudication of the cause.

Statistical analysis: Continuous variables are reported as mean +/- SD or as Median and interquartile range. Pre-valvuloplasty and post-valvuloplasty hemodynamic and echocardiographic results are compared using the KrusKal-Wallis, the Fisher or square chi square test according to the nature of variables (continuous or categorical). The significance level was set as $\mathrm{p}<0.05$. Kaplan-Meier time to event curves were constructed for two outcomes: 1)Overall survival 2) Event free survival, with event defined as mitral valve surgery or repeat mitral balloon valvuloplasty. All the analysis was performed with the STATA 11.0 software (StataCorp LP, Texas, USA).

\section{Results}

Baseline clinical characteristics for the 182 patients included in the registry are summarized in (Table 1). The majority of patients were women $162(89 \%)$ and $131(80.86 \% / 81.32 \%)$ patients had symptoms of significant congestive heart failure at baseline with predominantly NYHA class II heart failure. With respect to comorbidities, $35(19.23 \%)$ patients had hypertension, $10(5.49 \%)$ diabetes, 3(1.64\%) dyslipidemia, $16(8.79 \%)$ active smokers, $12(6.59 \%)$ cerebrovascular disease and $3(1.64 \%)$ had coronary artery disease. Balloon valvuloplasty with the Inoue balloon technique was used on $(99 \%)$ of the patients while the Multitrack double balloon technique was only used in 2 patients (1\%). Hospital mortality was 1\% (2 patients), 5.49\% (10 patients) developed pericardial effusion and pericardial tamponade occurred in $2 \%$ ( 4 patients). Other post procedural complications are listed in (Table 2). After mitral balloon valvuloplasty $7.7 \%$ of the patients (14 patients) had significant (grade III and IV) mitral insufficiency (Figure 1), the remainder had grade II or less mitral regurgitation.

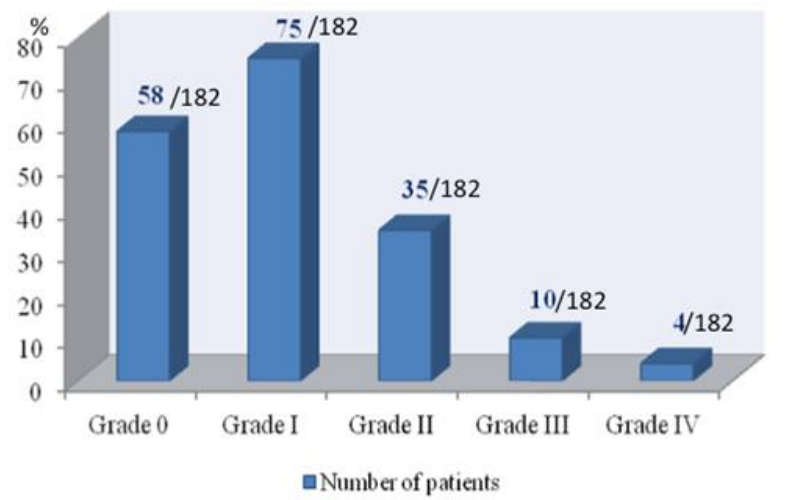

Figure 1: Severity of Postprocedure Mitral Valvular Insufficiency.

Table 1: Baseline Clinical Characteristics.

\begin{tabular}{|c|c|c|}
\hline & $\mathrm{n}$ & $\%$ \\
\hline Men & 20 & 11 \\
\hline Women & 162 & 89 \\
\hline \multicolumn{3}{|l|}{ History of: } \\
\hline - Hypertension & 35 & 19.23 \\
\hline -Diabetes & 10 & 5.49 \\
\hline -Dyslipidemia & 3 & 1.64 \\
\hline -Active smoking & 16 & 8.79 \\
\hline -Renal insufficiency & 2 & 1.09 \\
\hline -Coronary artery disease & 3 & 1.64 \\
\hline -Cerebrovascular disease & 12 & 6.59 \\
\hline \multicolumn{3}{|c|}{ New York Heart Association Class: } \\
\hline$-\mathrm{I}$ & 34 & 18.68 \\
\hline- -II & 102 & 56.04 \\
\hline- -III & 39 & 21.43 \\
\hline -IV & 7 & 3.84 \\
\hline
\end{tabular}


Table 2: Postprocedural complications.

\begin{tabular}{|l|l|l|}
\hline Complication & $\mathrm{n}$ & $\%$ \\
\hline Death & 2 & 1.09 \\
\hline Pericardial effusion & 10 & 5.49 \\
\hline Pericardial tamponade & 4 & 2.19 \\
\hline Urgent surgery & 4 & 2.19 \\
\hline Cardiac arrhythmia & 5 & 2.74 \\
\hline Peripheral embolism & 1 & 0.54 \\
\hline Pulmonary edema & 6 & 3.29 \\
\hline Groin Hematoma & 5 & 2.74 \\
\hline Arterio-venous fistula & 1 & 0.54 \\
\hline Major bleeding & 2 & 1.09 \\
\hline Stroke/Transient ischemic attack & 2 & 1.09 \\
\hline
\end{tabular}

Hemodynamic results recorded immediately before and after the balloon valvuloplasty are summarized in (Table 3). There was significant decrease in mitral valve gradient and increases in mitral valve area. The mean invasive diastolic mitral gradient decreased from $19 \pm 8.01 \mathrm{mmHg}$ before the procedure to $6 \pm 6.92 \mathrm{mmHg}$ after valvuloplasty. The echocardiographic mean gradient diminished from $14 \pm 4.89 \mathrm{mmHg}$ to $8 \pm 3.78$ $\mathrm{mmHg}$. Invasive pulmonary systolic pressure decreased from 65 $\pm 22.35 \mathrm{mmHg}$ (before) to $50 \pm 19.18 \mathrm{mmHg}$ post commissurotomy. Mitral valvular area as measured with echocardiography (planimetry method) was $0.95 \pm 0.24 \mathrm{~cm}^{2}$ before valvuloplasty and increased to $1.68 \pm 0.56 \mathrm{~cm}^{2}$ after treatment. There were no significant differences observed in left ventricular ejection fraction pre and post PMBV.

Table 3: Hemodynamic Changes before and after Percutaneous Mitral Balloon Valvuloplasty.

\begin{tabular}{|l|l|l|l|}
\hline & Before & After & $\mathrm{p}$ \\
\hline Mitral gradient (invasive) (mmHg) & $19 \pm 8.01$ & $6 \pm 6.92$ & 0.000 \\
\hline Mitral gradient (echo) (mmHg) & $14 \pm 4.89$ & $8 \pm 3.78$ & 0.000 \\
\hline $\mathrm{PSP}^{\dagger}$ (invasive) (mmHg) & $65 \pm 22.35$ & $50 \pm 19.18$ & 0.000 \\
\hline $\mathrm{PSP}^{\dagger}($ echo) (mmHg) & $66 \pm 29.39$ & $50 \pm 24.55$ & 0.000 \\
\hline $\mathrm{MVA}^{\ddagger}\left(\mathrm{cm}^{2}\right)$ & $0.95 \pm 0.24$ & $1.68 \pm 0.56$ & 0.000 \\
\hline $\mathrm{EF}^{\S}$ (echo) (\%) & $55 \pm 4.78$ & $59 \pm 5.1$ & 0.067 \\
\hline
\end{tabular}

$\uparrow$ PSP: Pulmonary systolic pressure in $\mathrm{mmHg}$.

\$ MVA: Mitral valve area calculated by planimetry (transthoracic echocardiography) in $\mathrm{cm}^{2}$.

$\S$ EF: Ejection Fraction measured by transthoracic echocardiography.

One hundred and eleven patients $(60.98 \%)$ were free of mitral valve surgery or new mitral balloon valvuloplasty at 4 years. Forty-nine patients $(26.92 \%)$ required valve surgery and 22 patients (12.08\%) required further mitral balloon valvuloplasty (Table 4). Among the groups of patients that required an additional balloon valvuloplasty, $91 \%$ of patients only required one additional procedure (Figure 2). Thirty six (19.75\%) of patients had an immediate non clinically significant iatrogenic atrial septal defect after PMBV. There after 11.72\%, 9.87\%, 8.02\%, $6.79 \%$ at one, two, three and four years respectively. The restenosis of mitral valve after the initial procedure was $4.8 \%$ at one year, $8 \%$ at two years and $4 \%$ at three years. It peaked at $15.2 \%$ at $5-10$ years and decreased to $4 \%$ at $11-15$ years.

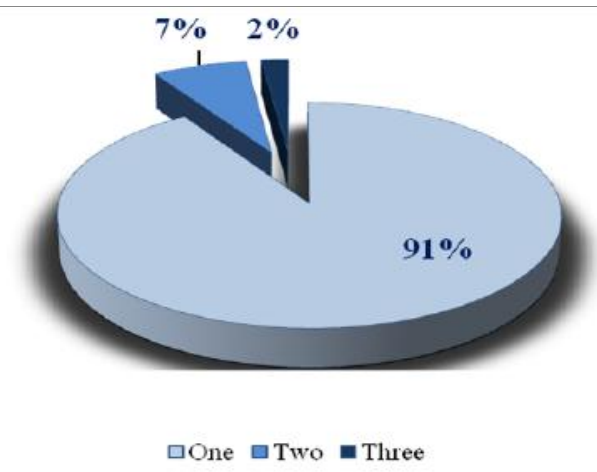

Figure 2: Percentage of Repetition of Percutaneous Mitral Balloon Valvuloplasty

Table 4: Outcomes of Patients at 50 months of follow-up.

\begin{tabular}{|l|l|l|}
\hline Outcome & $\mathrm{n}$ & $\%$ \\
\hline $\begin{array}{l}\text { Survival free of mitral valve surgery or new bal- } \\
\text { loon mitral valvuloplasty }\end{array}$ & 111 & 60.98 \\
\hline Mitral valve surgery & 49 & 26.92 \\
\hline New balloon mitral valvuloplasty & 22 & 12.08 \\
\hline
\end{tabular}

The overall 15 year survival was $38 \%$ (Figure 3 ). There were no significant differences between survivals when patients were divided with regards to echocardiographic score (Figure 4). Patients with successful initial procedure (increase in mitral valve area to $1.5 \mathrm{~cm}^{2}$ measured by echocardiography) had significantly better survival compared to those without successful initial procedure $(\mathrm{P}=0.047$, Figure 5$)$.

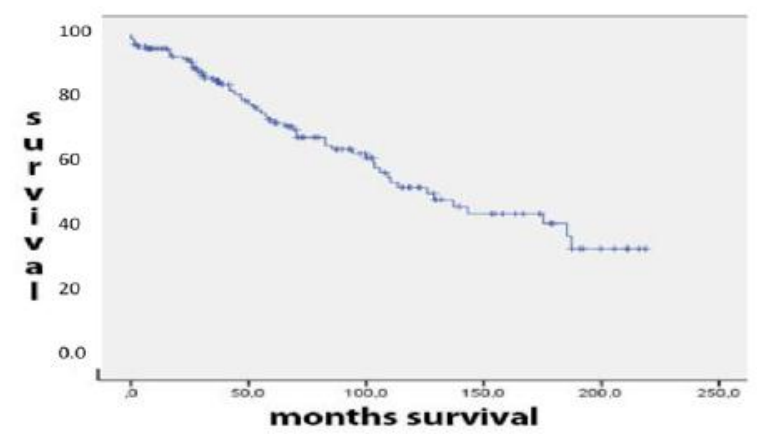

Figure 3: Kaplan - Meier CurveOverall Survival

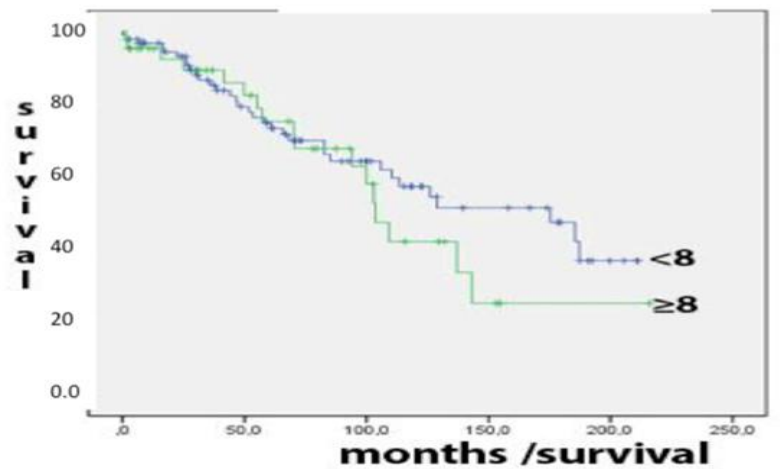

Figure 4: Survival by baseline echocardiographic Wilkins score. $\mathrm{p}=0.713(\log$ rank statistic $)$ 


\section{Conclusion}

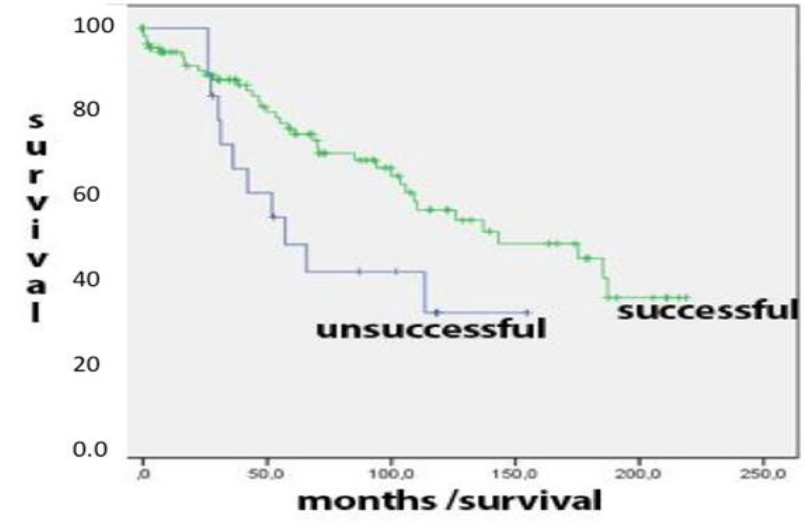

Figure 5: Survival by the initial success of the procedure. ("Success" is defined as a mitral valve area of at least $\left.1.5 \mathrm{~cm}^{2}\right) . p=0.047$ (log rank statistic)

\section{Discussion}

The study and long-term follow-up of patients after PMBV in the real world setting, especially in a third world country like Colombia are of an important relevance to the National Health Systems. This is especially important in the preventive cardiology era where focus is on hard clinical outcomes including procedure safety ${ }^{[1]}$. National registries data are important to support the long-term benefit of PMBV. From 1993 to 2011 this study enrolled 182 patients with the longest follow-up period of 15 years. As a registry, it can show what happens in "the real world" with the outcomes of these patients. The results are in concordance with previous publications around the world showing that this procedure is secure if performed by experienced operators. Furthermore, it has excellent early hemodynamic results. These benefits diminish with time, but it gives patients the opportunity to have a better quality of life as it has been demonstrated in previous studies ${ }^{[10,26-29]}$. The diminished benefit over time is related to insufficient valve opening ${ }^{[30]}$. Essop et al had reported a rate of restenosis with percutaneous mitral valvuloplasty at $0.08 \mathrm{~cm}^{2} /$ year compared to $0.07 \mathrm{~cm}^{2} /$ year for thoracotomy surgery ${ }^{[31]}$. The rate of interauricular iatrogenic septal defects after the procedure is similar to previous studies; usually these defects are very small with few millimeters of diameter and often without hemodynamic disturbance. It is suggested that its presence does not relate to important adverse outcomes ${ }^{[32]}$. The incidence of mild mitral regurgitation with balloon valvuloplasty $(41 \%)$ is similar to that of previous studies $(30-50 \%)^{[33]}$. The mitral insufficiency is thought to be related to procedural valve trauma ${ }^{[34]}$ survival. In this registry, the survival rate at one year after mitral balloon valvuloplasty was $96 \%$. $60.7 \%$ of patients were alive and free of mitral surgery and repeated mitral valvuloplasty at 50 months. Patients that had severe disease also had high Wilkins echocardiographic scores. In the follow-up period this accounted for a trend towards adverse outcomes independently of the initial success of the procedure. It is interesting that patients with valvular restenosis did not have a worse survival compared to those without restenosis. This finding has been previously reported in other registries ${ }^{[35,36]}$. Our data also confirms that a patient with failed valvuloplasty can be a successful candidate for future surgery ${ }^{[37,38]}$.
Percutaneous mitral valvuloplasty using the Inoue balloon technique improves the hemodynamic profile of severe mitral stenosis. Long-term follow-up suggest that it is a safe alternative to mitral valve surgery in well selected patients. Furthermore, this technique can be used to treat a patient multiple times, and if it is not successful, it does not preclude the use of alternative treatments.

\section{References}

1. Gerber, M.A., Baltimore, R.S., Eaton, C.B., et al. Prevention of rheumatic fever and diagnosis and treatment of acute Streptococcal pharyngitis: a scientific statement from the American Heart Association Rheumatic Fever, Endocarditis, and Kawasaki Disease Committee of the Council on Cardiovascular Disease in the Young, the Interdisciplinary Council on Functional Genomics and Translational Biology, and the Interdisciplinary Council on Quality of Care and Outcomes Research: endorsed by the American Academy of Pediatrics. (2009) Circulation 119(11): 1541-1551.

2. McKay, C.R., Kawanishi, D.T., Rahimtoola, S.H. Catheter balloon valvuloplasty of the mitral valve in adults using a double-balloon technique. Early hemodynamic results. (1987) JAMA 257(13): 1753-1761. 3. Dean, L.S., Mickel, M., Bonan, R., et al. Four-year follow-up of patients undergoing percutaneous balloon mitral commissurotomy. A report from the National Heart, Lung, and Blood Institute Balloon Valvuloplasty Registry. (1996) J Am Coll Cardiol 28(6): 1452-1457.

4. Multicenter experience with balloon mitral commissurotomy. NHLBI Balloon Valvuloplasty Registry Report on immediate and 30-day follow-up results. The National Heart, Lung, and Blood Institute Balloon Valvuloplasty Registry Participants. (1992) Circulation 85(2): 448-461.

5. Anon. WHO Global InfoBase. Accessed July 5, 2015.

6. Saeed, W., Tiwari, N., Salamon,J. Affect of Warfarin on Pulmonary Arterial Hypertension (PAH) Mortality: Facts Have Changed? (2011) J Card Fail 17(8): S66.

7. Badri, M., Saeed, W., Lahoti, A., et al. Effect of Obesity on Mortality In Pulmonary Arterial Hypertension: A Retrospective Analysis. (2012) J Am Coll Cardiol 59: E1590-E1590.

8. Sardar, M.R., Saeed, W., Kowey, P.R. Antiarrhythmic Drug Therapy for Atrial Fibrillation. (2014) Cardiol Clin 32(4): 533-549.

9. Inoue, K., Owaki, T., Nakamura, T. Clinical application of transvenous mitral commissurotomy by a new balloon catheter. (1984) J Thorac Cardiovasc Surg 87(3): 394-402.

10. Song, J.K., Kim, M.J., Yun, S.C., et al. Long-term outcomes of percutaneous mitral balloon valvuloplasty versus open cardiac surgery. (2010) J Thorac Cardiovasc Surg 139(1):103-110.

11. Rifaie, O., Abdel-Dayem, M.K., Ramzy, A., et al. Percutaneous mitral valvotomy versus closed surgical commissurotomy. Up to 15 years of follow-up of a prospective randomized study. (2009) J Cardiol 53(1): 28-34.

12. Cardoso, L.F., Grinberg, M., Pomerantzeff, P.M., et al. Comparison of open commissurotomy and balloon valvuloplasty in mitral stenosis. A five-year follow-up. (2004) Arq Bras Cardiol 83(3): 248-252; 243-247.

13. Ismeno, G., Renzulli, A., De Feo, M., et al. Surgery of rheumatic mitral stenosis: comparison of different techniques. (2001) Acta Cardiol 56(3): 155-161.

14. Tokmakoglu, H., Vural, K.M., Ozatik, M.A. Closed commissurotomy versus balloon valvuloplasty for rheumatic mitral stenosis. (2001) J Heart Valve Dis 10(3): 281-287.

15. Ommen, S.R., Nishimura, R.A., Grill, D.E. Comparison of longterm results of percutaneous mitral balloon valvotomy with closed transventricular mitral commissurotomy at a single North American 
Institution. (1999) Am J Cardiol 84(5): 575-577.

16. Ben Farhat, M., Ayari, M., Maatouk, F., et al. Percutaneous balloon versus surgical closed and open mitral commissurotomy: seven-year follow-up results of a randomized trial. (1998) Circulation 97(3): 245250.

17. Reyes, V.P., Raju, B.S., Wynne, J., et al. Percutaneous balloon valvuloplasty compared with open surgical commissurotomy for mitral stenosis. (1994) N Engl J Med 331(15): 961-967.

18. Arora, R., Nair, M., Kalra, G.S., et al. Immediate and long-term results of balloon and surgical closed mitral valvotomy: a randomized comparative study. (1993) Am Heart J 125(4): 1091-1094.

19. Momomura, S., Takenaka, K., Serizawa, T., et al. Percutaneous transvenous, mitral commissurotomy versus open mitral commissurotomy. (1992) Nihon Geka Gakkai Zasshi 93(9): 1016-1019.

20. Shrivastava, S., Mathur, A., Dev, V., et al. Comparison of immediate hemodynamic response to closed mitral commissurotomy, single-balloon, and double-balloon mitral valvuloplasty in rheumatic mitral stenosis. (1992) J Thorac Cardiovasc Surg 104(5): 1264-1267.

21. Patel, J.J., Shama, D., Mitha, A.S., et al. Balloon valvuloplasty versus closed commissurotomy for pliable mitral stenosis: a prospective hemodynamic study. (1991) J Am Coll Cardiol 18(5):1318-1322.

22. Hu, X., Zhao, Q. Systematic comparison of the effectiveness of percutaneous mitral balloon valvotomy with surgical mitral commissurotomy. (2011) Swiss Med Wkly141: w13180.

23. Sardar, M.R., Badri, M., Prince, C.T., et al. Underrepresentation of women, elderly patients, and racial minorities in the randomized trials used for cardiovascular guidelines. (2014) JAMA Intern Med 174(11):1868-1870.

24. Ying-Fu Chen, et al. Gender Differences in Patients with Acute Aortic Dissection-Insights from Clinical Features to Related Biological Mechanism. (2015) J Heart Cardiol 1(2): 1-2.

25. Wilkins, G.T., Weyman, A.E., Abascal, V.M., et al. Percutaneous balloon dilatation of the mitral valve: an analysis of echocardiographic variables related to outcome and the mechanism of dilatation. (1988) $\mathrm{Br}$ Heart J 60(4): 299-308.

26. Messika-Zeitoun, D., Meizels, A., Cachier, A., et al. Echocardiographic evaluation of the mitral valve area before and after percutaneous mitral commissurotomy: the pressure half-time method revisited. (2005) J Am Soc Echocardiogr 18(12): 1409-1414.
27. Vahanian, A., Michel, P.L., Cormier, B., et al. Results of percutaneous mitral commissurotomy in 200 patients. (1989) Am J Cardiol 63(12): 847-852.

28. Cohen, D.J., Kuntz, R.E., Gordon, S.P., et al. Predictors of longterm outcome after percutaneous balloon mitral valvuloplasty. (1992) N Engl J Med 327(19): 1329-1335.

29. Hernandez, R., Bañuelos, C., Alfonso, F., et al. Long-term clinical and echocardiographic follow-up after percutaneous mitral valvuloplasty with the Inoue balloon. (1999) Circulation 99(12): 1580-1586. 30. Iung, B., Garbarz, E., Michaud, P., et al. Percutaneous mitral commissurotomy for restenosis after surgical commissurotomy: late efficacy and implications for patient selection. (2000) J Am Coll Cardiol 35(5): 1295-1302.

31. Essop, R., Rothlisberger, C., Dullabh, A., et al. Can the long-term outcomes of percutaneous balloon mitral valvotomy and surgical commissurotomy be expected to be similar? (1995) J Heart Valve Dis 4(5): 446-452.

32. Korkmaz, S., Demirkan, B., Guray, Y., et al. Long-term follow-up of iatrogenic atrial septal defect: after percutaneous mitral balloon valvuloplasty. (2011) Tex Heart Inst J 38(5): 523-527.

33. Black, M.D., Campagna, M., Bedard, P., et al. Severe mitral insufficiency post-balloon valvuloplasty: the late changes found in a disrupted mitral valve. (1990) Cathet Cardiovasc Diagn 21(2): 99-102.

34. Acar, C., Jebara, V.A, Grare P, et al. Traumatic mitral insufficiency following percutaneous mitral dilation: anatomic lesions and surgical implications. (1992) Eur J Cardio-Thorac Surg 6(12): 660-663; discussion 663-664.

35. Fawzy, M.E., Hegazy, H., Shoukri, M., et al. Long-term clinical and echocardiographic results after successful mitral balloon valvotomy and predictors of long-term outcome. (2005) Eur Heart J 26(16): $1647-1652$.

36. Jneid, H., Cruz-Gonzalez, I., Sanchez-Ledesma, M., et al. Impact of pre- and postprocedural mitral regurgitation on outcomes after percutaneous mitral valvuloplasty for mitral stenosis. (2009) Am J Cardiol 104(8):1122-1127.

37. Cohen, J.M., Glower, D.D., Harrison, J.K., et al. Comparison of balloon valvuloplasty with operative treatment for mitral stenosis. (1993) Ann Thorac Surg 56(6): 1254-1262.

38. Puneet, A. et al. A promising new therapeutic target for heart failure (2015) J Heart Cardiol 1(2): 1- 2
Journal ISSN: 2378-6914 (online)

Journal Title: Journal of Heart and Cardiology

Short title : J Heart Cardiol
Ommega Online Publishers

Journal E-mail: cardiology@ommegaonline.com

Website: www.ommegaonline.org 